Pacific Journal of Mathematic 


\title{
COMPOSITE NUMBERS AND PRIME REGRESSIVE ISOLS
}

\author{
JOSEPH BARBACK
}

Let $w(x)$, be the principal function for the set of all composite nonnegative integers and let $D_{w}$ denote its canonical extension to the isols. M. Hassett proved in Comp. M. 26 (1973), as an application of a very general theorem, that if $A$ is any $T$-regressive isol then $D_{w}(A)$ is a regressive isol that is prime. The present paper contains a number theoretic proof of the following property: if $Y$ is any infinite multiple-free regressive isol then $D_{w}(Y)$ is a regressive isol that is prime.

1. Preliminaries. We will assume that the reader is familiar with the main results given in [1], [2] and [4]. We use the notation of [2]. $W$ will denote the set of all composite positive integers $4,6,8, \cdots$. The principal function of $W$ will be denoted by $w(x)$ and $D_{w}$ will denote the canonical extension of $w(x)$ to the isols. Let $A$ be any regressive isol. Then, from results in [1], the value of $D_{w}(A)$ is a regressive isol, and, if $A$ is infinite then $D_{w}(A)$ is also infinite.

LEMma 1. Let $A$ be an infinite regressive isol. Then there exist infinite regressive isols $U$ and $V$ such that

$$
\begin{aligned}
A+2 & =U+V, \quad \text { and } \\
D_{w}(A) & =U+2 V .
\end{aligned}
$$

Proof. We will first show that increasing recursive functions $u(x)$ and $v(x)$ can be defined such that

$$
\begin{aligned}
& x+2=u(x)+v(x), \quad \text { and } \\
& w(x)=u(x)+2 v(x) .
\end{aligned}
$$

Define $u(0)=0$ and $v(0)=2$. Observe that for each number $x$, the value of $e(x)=w(x+1)-w(x)$ is either 1 or 2 . Assuming that the values of $u(x)$ and $v(x)$ have been defined, let $u(x+1)=u(x)+1$ and $v(x+1)=v(x)$ if $e(x)=1$, and $u(x+1)=u(x)$ and $v(x+1)=v(x)+1$ if $e(x)=2$. It is easy to verify that $u(x)$ and $v(x)$ are increasing recursive functions and satisfy statements (3) and (4). From (3) and (4), and the Nerode metatheorem for such statements, it follows that 


$$
\begin{aligned}
A+2 & =D_{u}(A)+D_{v}(A), \quad \text { and } \\
D_{w}(A) & =D_{u}(A)+2 D_{v}(A) .
\end{aligned}
$$

$D_{u}(A)$ and $D_{v}(A)$ are regressive isols, since $A$ is a regressive isol and each of the functions $u(x)$ and $v(x)$ is increasing recursive. Also, each of these isols is infinite. This fact follows by first noting that among the numbers $e(0), e(1), \cdots$ each of the values 1 and 2 will occur infinitely often. Combining this feature with the definitions of the functions $u(x)$ and $v(x)$, and with the way in which the canonical extension of a recursive function can be represented as an infinite series of isols (cf. [1]), it follows that both $D_{u}(A)$ and $D_{v}(A)$ are infinite. If we let $U=D_{u}(A)$ and $V=D_{v}(A)$, then the desired result of the lemma is obtained.

Let $\left[\begin{array}{l}x \\ 2\end{array}\right]$ denote the function that is the greatest integer obtained when the number $x$ is divided by 2 . Note, $\left[\begin{array}{l}x \\ 2\end{array}\right]$ is an increasing recursive function. Therefore its canonical extension to the isols, written as $\left[\begin{array}{l}X \\ 2\end{array}\right]$, will map regressive isols to regressive isols.

Lemma 2. For all numbers $d, m$ and $n$,

$$
2 d=m+n \rightarrow d=\left[\begin{array}{c}
m \\
2
\end{array}\right]+\left[\begin{array}{c}
n+1 \\
2
\end{array}\right]
$$

LeMma 3. For all numbers $m$,

$$
\left[\begin{array}{c}
3 m \\
2
\end{array}\right]=2\left[\begin{array}{c}
m \\
2
\end{array}\right]+\left[\begin{array}{c}
m+1 \\
2
\end{array}\right]
$$

Proofs for each of these lemmas is easy to obtain and will be omitted. Because the functions that appear in their statements are increasing recursive, it follows that each of the lemmas has an analogue that is true in the regressive isols (when the recursive functions are replaced by their respective canonical extensions to the isols). We therefore have, for all regressive isols $D, M$ and $N$,

$$
2 D=M+N \rightarrow D=\left[\begin{array}{c}
M \\
2
\end{array}\right]+\left[\begin{array}{c}
N+1 \\
2
\end{array}\right], \quad \text { and }
$$

$$
\left[\begin{array}{c}
3 M \\
2
\end{array}\right]=2\left[\begin{array}{c}
M \\
2
\end{array}\right]+\left[\begin{array}{c}
M+1 \\
2
\end{array}\right]
$$


If $X$ is an infinite regressive isol, then $\left[\begin{array}{l}X \\ 2\end{array}\right]$ is also an infinite regressive isol. This fact follows by observing that in the infinite series representation of $\left[\begin{array}{l}X \\ 2\end{array}\right]$ the e-difference function associated with $\left[\begin{array}{l}x \\ 2\end{array}\right]$ will be positive infinitely often.

REMARK. Later, in the proof of the main theorem, we will apply the representations given in Lemma 1 and the features expressed in (7) and (8). In addition, we will also use the cancellation property for isols, given by Dekker and Myhill in [5, Theorem 40], which states that if $A$ and $B$ are any isols, then

$$
2 A \leqq 2 B \rightarrow A \leqq B
$$

Statement (9) is applied later just in the special case that both $A$ and $B$ are regressive isols. We would like to show that this special case of the cancellation property may be obtained from (7). Observe first that $\left[\begin{array}{c}2 x \\ 2\end{array}\right]=x$ is an identity that is true for all numbers $x$. Therefore also, $\left[\begin{array}{c}2 X \\ 2\end{array}\right]=X$ is an identity that is true for all regressive isols $X$. Assume $A$ and $B$ are regressive isols and that $2 A \leqq 2 B$. Then there is an isol $T$ such that $2 A+T=2 B$, and, in view of $[4, \mathrm{P} 23$ and P24], we may assume that $T$ is a regressive isol. If we now combine these facts with (7), then the cancellation property in the special case $A$ and $B$ are regressive isols may be obtained in the following way:

$$
\begin{aligned}
2 A \leqq 2 B & \rightarrow 2 A+T=2 B \\
& \rightarrow B=\left[\begin{array}{c}
2 A \\
2
\end{array}\right]+\left[\begin{array}{c}
T+1 \\
2
\end{array}\right] \\
& \rightarrow B=A+\left[\begin{array}{c}
T+1 \\
2
\end{array}\right] \\
& \rightarrow A \leqq B .
\end{aligned}
$$

2. Multiple-free isols and the main theorem. An infinite isol $Y$ is called multiple-free if for every isol $B, 2 B \leqq Y$ implies $B$ is finite. Multiple-free isols were introduced and studied in [5]. An example of an infinite multiple-free isol that is regressive appears in [3]. Note that if $Y$ is multiple-free and $A$ is any infinite isol with $A \leqq Y$, then $A$ is also multiple-free. Prime isols were introduced in [5]. Because any isol that is a predecessor of a regressive isol is also regressive, it is possible to characterize regressive isols that are prime in 
the following way: a regressive isol $P$ is prime if it is not possible to factor $P$ as $P=(X+2)(Y+2)$, for any regressive isols $X$ and $Y$.

THEOREM. Let $A$ be an infinite multiple-free regressive isol. Then $D_{w}(A)$ is an infinite regressive isol that is prime.

Proof. Since $A$ is an infinite regressive isol, it follows that $D_{w}(A)$ is also an infinite regressive isol. Note that, from Lemma 1, (1) and (2), it follows that

$$
D_{w}(A)+U=2(A+2),
$$

where $U$ is an infinite regressive isol. To show that $D_{w}(A)$ is prime, let us assume otherwise.

Case 1. $D_{w}(A)=2 Y$, for some infinite regressive isol $Y$. If we then substitute in $(10)$, we obtain

$$
2 Y+U=2(A+2) \text {. }
$$

Therefore $2 Y \leqq 2(A+2)$ and also, from (9), $Y \leqq A+2$. If we now solve in (11) for $U$, we obtain

$$
U=2(A+2-Y)
$$

Hence $U$ is an infinite regressive isol that is not multiple-free. However, from (1), $U$ is a predecessor of $A+2$. Since $A$ is multiple-free, $A+2$ will be also. But then $U$ is multiple-free.

Case 2. $D_{w}(A)=(3+S) Y$, for some regressive isol $S$ and infinite regressive isol $Y$. Beginning with the given representation of $D_{w}(A)$, and then successively applying the statements (10), (7), and (8), gives

$$
\begin{aligned}
D_{w}(A)=(3+S) Y & \rightarrow 2(A+2)=3 Y+S Y+U \\
& \rightarrow A+2=\left[\begin{array}{c}
3 Y \\
2
\end{array}\right]+\left[\begin{array}{c}
S Y+U+1 \\
2
\end{array}\right] \\
& \rightarrow A+2=2\left[\begin{array}{l}
Y \\
2
\end{array}\right]+\left[\begin{array}{c}
Y+1 \\
2
\end{array}\right]+\left[\begin{array}{c}
S Y+U+1 \\
2
\end{array}\right] .
\end{aligned}
$$

Therefore,

$$
2\left[\begin{array}{l}
Y \\
2
\end{array}\right] \leqq A+2
$$


Since $Y$ is an infinite regressive isol, $\left[\begin{array}{l}Y \\ 2\end{array}\right]$ is also. From (12), we obtain a contradiction to the multiple-free property of $A+2$.

By these two cases, we may conclude that $D_{w}(A)$ is an infinite prime regressive isol.

\section{REFERENCES}

1. J. Barback, Recursive functions and regressive isols, Math. Scand., 15 (1964), 29-42.

2. — On recursive sets and regressive isols, Michigan Math. J., 15 (1968), 27-32.

3. - Two notes on recursive functions and regressive isols, Trans. Amer. Math. Soc., 144 (1969), 77-94.

4. J. C. E. Dekker, Regressive isols, in Sets, Models and Recursion Theory, ed. J. N. Crossley (Amsterdam 1967), 272-296.

5. J. C. E. Dekker and J. Myhill, Recursive Equivalence Types, Univ. of California publications in Mathematics, N.S. 3 (1960), 67-214.

6. M. Hassett, Extension pathology in regressive isols, Compositio Math., 26 (1973), 31-39.

Received June 23, 1975 and in revised form October 14, 1975.

SUNy College at Buffalo 




\section{Pacific Journal of Mathematics}

\section{Vol. 62, No. $1 \quad$ January, 1976}

Mieczyslaw Altman, Contractor directions, directional contractors and

directional contractions for solving equations . .................. 1

Michael Peter Anderson, Subgroups of finite index in profinite groups .........

Zvi Arad, Abelian and nilpotent subgroups of maximal order of groups of odd order

John David Baildon and Ruth Silverman, On starshaped sets and Helly-type theorems ..........................................

John W. Baker and R. C. Lacher, Some mappings which do not admit an

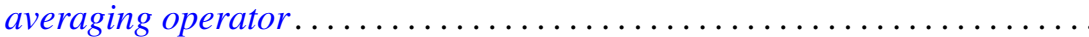

Joseph Barback, Composite numbers and prime regressive isols . . . . . . . . . .

David M. Boyd, Composition operators on $H^{p}(A) \ldots \ldots \ldots \ldots \ldots \ldots \ldots$

Maurice Chacron, Co-radical extension of PI rings . . . . . . . . . . . . .

Fred D. Crary, Some new engulfing theorems . . . . . . . . . . . . . . .

Victor Dannon and Dany Leviatan, A representation theorem for convolution transform with determining function in $L^{p} \ldots \ldots \ldots \ldots \ldots \ldots \ldots \ldots \ldots \ldots \ldots \ldots \ldots \ldots$

Mahlon M. Day, Lumpy subsets in left-amenable locally compact

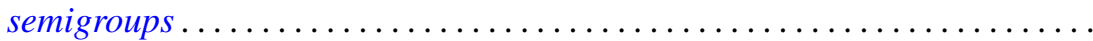

Michael A. Gauger, Some remarks on the center of the universal enveloping algebra of a classical simple Lie algebra . .

David K. Haley, Equational compactness and compact topologies in rings

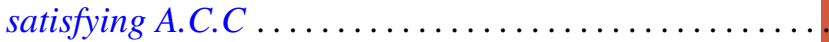

Raymond Heitmann, Generating ideals in Prüfer domains .

Gerald Norman Hile, Entire solutions of linear elliptic equations with

Laplacian principal part. .

Richard Oscar Hill, Moore-Postnikov towers for fibrations in which $\pi_{1}$ (fiber) is non-abelian

John Rast Hubbard, Approximation of compact homogeneous maps . .

Russell L. Merris, Relations among generalized matrix functions . .

V. S. Ramamurthi and Edgar Andrews Rutter, On cotorsion radicals ...

Ralph Tyrrell Rockafellar and Roger Jean-Baptiste Robert Wets, Stochastic

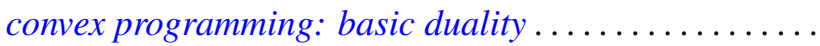

Alban J. Roques, Local evolution systems in general Banach spaces ..

I. Bert Russak, An indirect sufficiency proof for problems with bounded state variables.

Richard Alexander Sanerib, Jr., Ultrafilters and the basis property. .

H. A. Seid, The decomposition of multiplication operators on $L_{p}$-spaces . .

Franklin D. Tall, The density topology .................. 